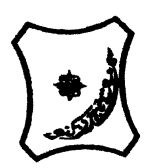

Bayero Journal of Pure and Applied Sciences, 10(1): 183 - 190

Received: December, 2016

Accepted: April, 2017

ISSN $2006-6996$

\title{
MOLECULAR DYNAMICS OF A PROGUANIL DERIVATIVE
}

\author{
* Muhammad, A. ${ }^{1}$, Taura, $^{\text {L } . S .}{ }^{1}$ and Ndikilar, C.E. ${ }^{2}$ \\ ${ }^{1}$ Department of Physics, Sule Lamido University Kafin-Hausa, Jigawa State \\ ${ }^{2}$ Department of Physics, Federal University Dutse, Jigawa State \\ *Correspondence author:aminumuhammad1427@gmail.com (08130661127)
}

\begin{abstract}
Proguanil is a prophylactic antimalarial drug that is very effective against sporozoites and works by stopping the malaria parasites from reproducing inside the red blood cells. In this work, the molecular dynamics of a derivative of Proguanil is studied. A Hydrogen atom at position 3 on the benzene ring of the molecule of Proguanil is substituted by chlorine atom to give the desired derivative. The molecular geometries of Proguanil derivative are studied using ab-initio Quantum chemical calculations at the Restricted Hatree-Fock (RHF) level of theory using the basis sets 6$31 G(d, p)$ and 6-31++G. Also, Density Functional Theory (DFT) calculations at B3LYP with 6$31 G(d, p)$ and $6-31++G$ basis sets were carried out for inclusion of electron correlation. The dipole moments, thermal energies, quadrupole moment, polarizibility and optimized bond length computations for the molecule are obtained. The dipole moment of the Proguanil's derivative at both levels of theory is less than that obtained for original malaria drug Proguanil. This indicates that the derivative Proguanil responds significantly more than Proguanil to an applied electric field. The Infra Red (IR) and Raman vibrational frequencies are vividly examined and the most intense IR and Raman frequencies are identified. The computation was performed using Gaussian 03W software.
\end{abstract}

Keywords: Proguanil, Density Functional Theory, Restricted Hartree Fock, Gaussian

\section{INTRODUCTION}

Malaria has been well known to be the most important parasitic infection of man in tropical regions over the years. Malaria has had great impact on the history of humanity as it is one of the oldest known diseases to mankind. Currently, it is estimated that about 2 billion people are at risk of malaria resulting in about 500 million cases annually and one million deaths. The majority of malaria cases exist in developing countries of the tropics and sub-tropics with the majority of casualties being among children. Malaria thus represents a significant impediment to the socio economic development of these tropical countries (Singh, 2002).

There is a limited number of drugs which can be used to treat or prevent malaria. The most widely used are Quinine and it is derivatives (Chloroquine, Primaquine, Mefloquine), and the antifolate drugs (Proguanil, Chloproguanil, Clociguanil, BRL 6231 (WR99210), Pryrimethamine, Sulfadoxine, Sulfalene, Dapsone and their combination with other drugs (Atovaqone and Proguanil Hydrochloride, Pryrimethamine/Sulfadoxine, Pryrimethamine/ Sulfadoxine/Artesunate) (Schwarz, 2002).

Pyrimethamine was first developed in 1952 by Crud, Davy and Rose from the synthesis of the antifolate drug Paludrine or from Proguanil (chlorguamide Hydrochloride) (Snow, 2005). It is an antiparasitic compound and a hydrofolate reductase inhibitor (Sachs \& Malaney, 2002). It is a Folic acid antagonist and the rationale for its therapeutic action is based on the differential requirement between host and parasite for nucleic acid precursors involved in growth. Pyrimethamine possesses blood schizonticidal and some tissue schizonticidal activity against malaria parasite in human (Singh et al 2002). Its inhibition activity leads to either killing a pathogenic organism (malaria parasite) or to modify some aspects of metabolism of the body that are functioning dormally. Daraprim interferes with the biosynthesis of the parasite.

Pyrimethamine on the other hand, inhibits the dihydrofolate reductase of plasmodia and thereby blocking the biosynthesis of purine and pyrimidine which are essential for DNA synthesis and cell multiplication (Chifu, 2014). This leads to failure of nuclear division at the time of schizont formation in the erythrocytes and liver. Daraprim is a weak basic drug and sparingly soluble in water.

For almost three quarters of a century, Daraprim is used as one of the anti malaria resistance drug in some countries (places) where Quinine and its derivatives failed to treat malaria. It is recommended for patients infected in areas where susceptible plasmodia exist (Geh, 2015). Although the drug has antimalarial activity when used alone, parasitological resistance can develop rapidly(Schwarz, 2002). When used in combination, it produces a synergistic effect on the parasite and can be effective even in the presence of resistance to individual component. It is usually used in combination with Sulfadoxine.

Proguanil is a prophylactic antimalarial drug that is very effective against sporozoites and works by stopping the malaria parasites from reproducing inside the red blood cells (Schwarz, 2002). 
In an earlier article (Chifu, 2014) a thorough study of the molecular dynamics of this molecule was carried out in gas phase at Restricted Hartree Fock (RHF) and Density Functional Theory (DFT) levels of theory. In this research article; we provide a systematic study of a derivative of Proguanil, 3-Chloroproguanil and compare the molecular dynamics of this molecule to that of Proguanil

\section{Computational Methodology}

The Gaussian software is used in this study. Mainly, the Gaussian program is characterized by using different basis sets. This is the mathematical representation of the molecular orbital within the molecules and can be interpreted as restricting each electron to a particular region of space. This implies that larger basis sets impose fewer constraints on electrons and more accurately approximate exact molecular orbitals. The optimized structure and molecular dynamics of the molecule is obtained. The molecular structures and geometries of the malaria drug, 3-Chloro Proguanil is completely optimized using ab- initio quantum mechanical calculations at the Restricted Hartree-Fock (RHF) level of theory using the basis sets $6-31++G$ and $6-31 G(d, p)$. The structures are further refined using Density Functional Theory (DFT) which is a cost effective method for inclusion of electron correlations with the three parameter density functional generally known as Becke3LYP (B3LYP) (Becke,1993), (Becke,1988) \&(Lee et al,1988) using the same basis sets. At the first step, geometry optimizations are carried out, then later the Infra Red (IR) and Raman frequencies are calculated using the Hessian which is the matrix of second derivatives of the energy with respect to geometry.

The energies of the highest occupied molecular orbital (HOMO) and lowest unoccupied molecular orbital (LUMO) are computed. Also, total energies, dipole and quadrupole moments are computed. A detailed analysis of the IR and Raman active vibrational frequencies is carried out to determine the most intense frequencies and their descriptions. All computations in this work were modeled in gas phase.

\section{RESULTS AND DISCUSSION}

\section{Optimized Molecular Structures}

Geometry optimizations usually attempt to locate minima on the potential energy surface, thereby predicting equilibrium structures of molecular systems (Frisch et al 2004). At the minima, the first derivative of the energy (gradient) is zero. Since the gradient is the negative of the forces, the forces are also zero at such a point (stationary point). In Gaussian, a geometry optimization begins at the molecular structure specified at the input and steps along the potential energy surface. It computes the energy and the gradient at that point and determines which direction to make the next step. The gradient indicates the direction along the surface in which the energy decreases most rapidly from the current point as well as the steepness of that slope. Atoms in the molecule are numbered according to their order in the molecule specification section of the input.

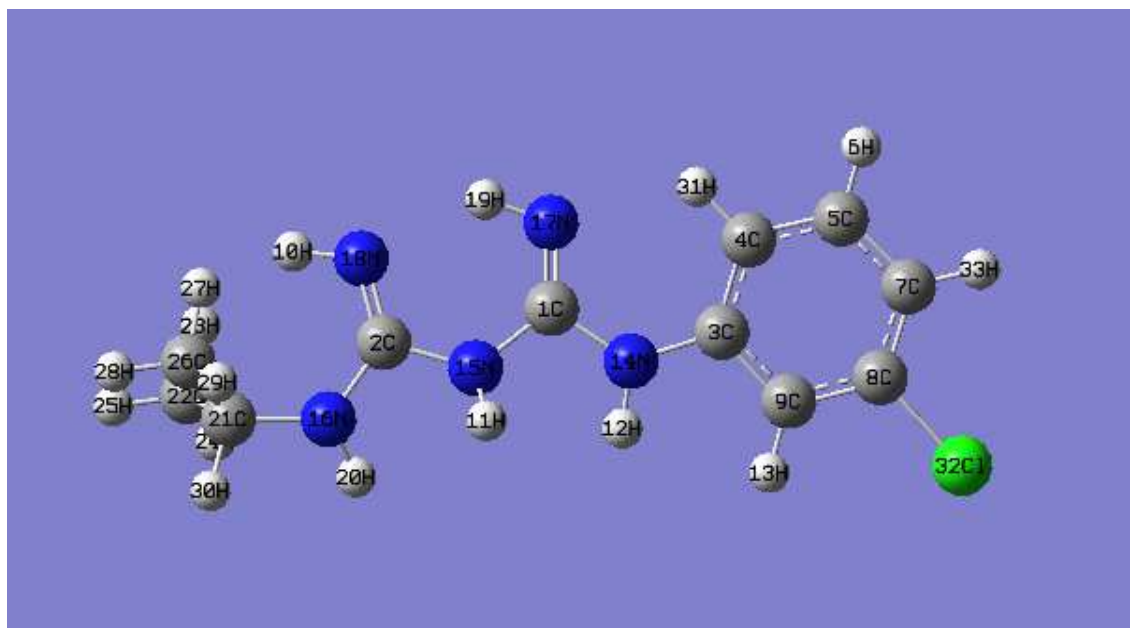

Fig.1 Optimized Structure for derivative of Proguanil 
BAJOPAS Volume 10 Number 1 June, 2017

Table 1: Optimized Bond Lengths $(\AA)$ for derivative of Proguanil

\begin{tabular}{|c|c|c|c|c|}
\hline $\begin{array}{l}\text { Geometrical } \\
\text { Parameter }\end{array}$ & $\begin{array}{c}\text { RHF } \\
6-31++G\end{array}$ & $6-31 G(d, p)$ & $\begin{array}{l}\text { B3LYP } \\
6-31++G\end{array}$ & $6-31 G(d, p)$ \\
\hline$R(1,14)$ & 1.3914 & 1.3879 & 1.8892 & 1.8461 \\
\hline$R(1,15)$ & 1.4084 & 1.4084 & 1.7313 & 1.6985 \\
\hline $\mathrm{R}(1,17)$ & 1.2463 & 1.2608 & 1.897 & 1.8491 \\
\hline$R(2,15)$ & 1.3931 & 1.3909 & 1.8942 & 1.8522 \\
\hline$R(2,16)$ & 1.3805 & 1.3767 & 1.7367 & 1.6989 \\
\hline $\mathrm{R}(2,18)$ & 1.2588 & 1.2742 & 1.8808 & 1.8444 \\
\hline$R(3,4)$ & 1.3923 & 1.3951 & 1.4041 & 1.4019 \\
\hline$R(3,9)$ & 1.3933 & 1.399 & 1.4054 & 1.4044 \\
\hline$R(3,14)$ & 1.4009 & 1.4018 & 1.8881 & 1.8428 \\
\hline$R(4,5)$ & 1.3832 & 1.3887 & 1.4023 & 1.3952 \\
\hline $\mathrm{R}(4,31)$ & 1.0683 & 1.0661 & 1.0857 & 1.0862 \\
\hline$R(5,6)$ & 1.0757 & 1.073 & 1.0835 & 1.0841 \\
\hline$R(5,7)$ & 1.3847 & 1.3882 & 1.3925 & 1.3928 \\
\hline $\mathrm{R}(7,8)$ & 1.380 & 1.3795 & 1.3948 & 1.396 \\
\hline$R(7,33)$ & 1.073 & 1.0704 & 1.8259 & 1.7567 \\
\hline $\mathrm{R}(8,9)$ & 1.3793 & 1.3758 & 1.4003 & 1.3923 \\
\hline $\mathrm{R}(8,32)$ & 1.7469 & 1.8129 & 1.0837 & 1.0843 \\
\hline $\mathrm{R}(9,13)$ & 1.075 & 1.0726 & 1.0856 & 1.0859 \\
\hline$R(10,18)$ & 0.9961 & 0.9977 & 1.4614 & 1.4346 \\
\hline$R(11,15)$ & 0.995 & 0.9934 & 1.4512 & 1.4248 \\
\hline$R(12,14)$ & 0.9936 & 0.9924 & 1.4519 & 1.4247 \\
\hline$R(16,20)$ & 0.9952 & 0.9931 & 1.4595 & 1.4323 \\
\hline$R(16,21)$ & 1.4634 & 1.4701 & 1.4493 & 1.4225 \\
\hline $\mathrm{R}(17,19)$ & 1.0009 & 1.0023 & 1.5346 & 1.5324 \\
\hline$R(21,22)$ & 1.533 & 1.5346 & 1.5349 & 1.5332 \\
\hline $\mathrm{R}(21,26)$ & 1.5296 & 1.5322 & 1.0998 & 1.0996 \\
\hline $\mathrm{R}(21,30)$ & 1.0853 & 1.0844 & 1.9618 & 1.9034 \\
\hline $\mathrm{R}(22,23)$ & 1.0837 & 1.0826 & 1.0966 & 1.0951 \\
\hline$R(22,24)$ & 1.0853 & 1.0833 & 1.0958 & 1.0941 \\
\hline$R(22,25)$ & 1.0855 & 1.0847 & 1.099 & 1.0968 \\
\hline$R(26,27)$ & 1.0829 & 1.0816 & 1.0969 & 1.0956 \\
\hline$R(26,28)$ & 1.0851 & 1.0843 & 1.098 & 1.0958 \\
\hline$R(26,29)$ & 1.0838 & 1.0828 & 1.0953 & 1.0941 \\
\hline
\end{tabular}

Table 2: Optimized Bond Angles $\left({ }^{\circ}\right.$ ) for derivative of Proguanil

\begin{tabular}{llccc}
\hline Geometrical & RHF & \multicolumn{3}{c}{ B3LYP } \\
Parameter & $6-31++\mathrm{G}$ & $6-31 \mathrm{G}(\mathrm{d}, \mathrm{p})$ & $6-31++\mathrm{G}$ & $6-31 \mathrm{G}(\mathrm{d}, \mathrm{p})$ \\
\cline { 2 - 5 } $\mathrm{A}(14,1,15)$ & 107.9224 & 109.4692 & 120.725 & 120.7868 \\
$\mathrm{~A}(14,1,17)$ & 123.7486 & 123.354 & 112.823 & 112.3253 \\
$\mathrm{~A}(15,1,17)$ & 128.329 & 127.1768 & 126.4508 & 126.8837 \\
$\mathrm{~A}(15,2,16)$ & 109.5284 & 111.4411 & 114.0578 & 112.4651 \\
$\mathrm{~A}(15,2,18)$ & 121.4075 & 120.4315 & 122.6837 & 123.8422 \\
$\mathrm{~A}(16,2,18)$ & 129.054 & 128.1239 & 123.1598 & 123.6045 \\
$\mathrm{~A}(4,3,9)$ & 119.1722 & 119.114 & 119.1825 & 118.6146 \\
$\mathrm{~A}(4,3,14)$ & 124.1357 & 124.5217 & 118.1155 & 118.1911 \\
$\mathrm{~A}(9,3,14)$ & 116.6305 & 116.3631 & 122.6868 & 123.1752 \\
$\mathrm{~A}(3,4,5)$ & 119.3522 & 119.4315 & 120.769 & 121.1148 \\
$\mathrm{~A}(3,4,31)$ & 119.9025 & 119.4936 & 120.0082 & 119.8006 \\
$\mathrm{~A}(5,4,31)$ & 120.7285 & 121.0689 & 119.2228 & 119.0842 \\
$\mathrm{~A}(4,5,6)$ & 118.7557 & 118.8483 & 120.7705 & 120.8575 \\
$\mathrm{~A}(4,5,7)$ & 122.0827 & 121.8793 & 118.6191 & 118.9427 \\
$\mathrm{~A}(6,5,7)$ & 119.1615 & 119.2711 & 120.6101 & 120.1991 \\
$\mathrm{~A}(5,7,8)$ & 117.6869 & 117.518 & 122.0317 & 121.2625 \\
$\mathrm{~A}(5,7,33)$ & 121.565 & 121.589 & 119.0325 & 119.4356 \\
$\mathrm{~A}(8,7,33)$ & 120.7479 & 120.8927 & 118.9355 & 119.3016 \\
$\mathrm{~A}(7,8,9)$ & 121.7387 & 122.3624 & 118.7275 & 119.0879 \\
$\mathrm{~A}(7,8,32)$ & 119.541 & 119.2025 & 120.4899 & 120.0849 \\
$\mathrm{~A}(9,8,32)$ & 118.7202 & 118.4347 & 120.7825 & 120.8271 \\
$\mathrm{~A}(3,9,8)$ & 119.9671 & 119.6925 & 120.6684 & 120.975 \\
$\mathrm{~A}(3,9,13)$ & 120.558 & 120.6276 & 120.3011 & 119.9998 \\
$\mathrm{~A}(8,9,13)$ & 119.4748 & 119.679 & 119.029 & 119.0247 \\
$\mathrm{~A}(1,14,3)$ & 127.8552 & 129.1023 & 112.0543 & 111.8219 \\
$\mathrm{~A}(1,14,12)$ & 113.9375 & 115.9867 & 109.3755 & 108.6522 \\
\hline
\end{tabular}


BAJOPAS Volume 10 Number 1 June, 2017

\section{Table 2 continue}

\begin{tabular}{llllr}
$\mathrm{A}(3,14,12)$ & 113.6723 & 114.5644 & 114.1404 & 115.2977 \\
$\mathrm{~A}(1,15,2)$ & 126.7722 & 126.9839 & 108.8662 & 108.0109 \\
$\mathrm{~A}(1,15,11)$ & 113.9248 & 116.0372 & 110.8043 & 111.5404 \\
$\mathrm{~A}(2,15,11)$ & 113.876 & 115.9096 & 100.9323 & 100.6722 \\
$\mathrm{~A}(2,16,20)$ & 112.9761 & 116.4117 & 111.044 & 111.1592 \\
$\mathrm{~A}(2,16,21)$ & 126.282 & 127.5338 & 112.0005 & 111.8983 \\
$\mathrm{~A}(20,16,21)$ & 113.4494 & 115.5222 & 110.0253 & 110.3023 \\
$\mathrm{~A}(1,17,19)$ & 110.8786 & 114.3865 & 108.3533 & 108.1491 \\
$\mathrm{~A}(2,18,10)$ & 112.8647 & 116.6101 & 107.515 & 107.3999 \\
$\mathrm{~A}(16,21,22)$ & 114.1193 & 113.332 & 107.7576 \\
$\mathrm{~A}(16,21,26)$ & 112.1535 & 112.3535 & 107.7391 & 111.3848 \\
$\mathrm{~A}(16,21,30)$ & 103.4092 & 103.5754 & 111.2659 & 110.0836 \\
$\mathrm{~A}(22,21,26)$ & 113.1635 & 112.8366 & 109.8509 & 111.9512 \\
$\mathrm{~A}(22,21,30)$ & 106.7585 & 106.9966 & 111.9632 & 107.1586 \\
$\mathrm{~A}(26,21,30)$ & 106.2633 & 106.9435 & 107.2475 & 108.0078 \\
$\mathrm{~A}(21,22,23)$ & 112.8483 & 112.6128 & 108.2612 & 108.0729 \\
$\mathrm{~A}(21,22,24)$ & 110.5714 & 110.5767 & 108.0836 & 105.2256 \\
$\mathrm{~A}(21,22,25)$ & 109.9007 & 109.8539 & 104.1645 & 96.8602 \\
$\mathrm{~A}(23,22,24)$ & 107.7179 & 107.9266 & 96.565 & 98.4242 \\
$\mathrm{~A}(23,22,25)$ & 107.6552 & 107.5062 & 97.8228 & 97.5415 \\
$\mathrm{~A}(24,22,25)$ & 107.9784 & 108.2151 & 97.3433 & 104.2657 \\
$\mathrm{~A}(21,26,27)$ & 113.0115 & 112.6025 & 102.8386 & 96.7983 \\
$\mathrm{~A}(21,26,28)$ & 109.5327 & 109.6437 & 96.4195 & 98.3789 \\
$(21,26,29)$ & 110.1776 & 110.3975 & 97.79 & 98.2504 \\
$\mathrm{~A}(27,26,28)$ & 107.6469 & 107.7488 & 97.5946 & 98.2848 \\
$\mathrm{~A}(27,26,29)$ & 107.9441 & 107.9973 & 97.9839 & 104.01 \\
$\mathrm{~A}(28,26,29)$ & 108.3932 & 108.3214 & 103.0678 & 96.0287 \\
\hline
\end{tabular}

\section{Dipole Moments}

The dipole moment is the first derivative of the energy with respect to an applied electric field. It is a measure of the asymmetry in the molecular charge distribution and is given as a vector in three dimensions. For Hartree-Fock calculations, this is equivalent to the expectation values of $\mathrm{X}, \mathrm{Y}$ and $\mathrm{Z}$, which are the quantities reported in the output. The predicted dipole moments (in Debye) at B3LYP level of theory are shown in Table 3 . The dipole moment of the molecules gives the strength of the polarity of the molecules. The predicted dipole moment for 3Chloro Proguanil is less than that of the original molecule at both $\mathrm{RHF} /(6-31++\mathrm{G} \& 6-31 \mathrm{G}(\mathrm{d}, \mathrm{p}))$ $B 3 L Y P /(6-31++G$ \& 6-31G(d,p)) level. The molecule is polar and the charge distribution is fairly symmetrical in gas phase. The dipole moments of Proguanil is greater than that of 3-Chloro Proguanil indicating that this molecule is less polar compared to Proguanil.

Table 3 : Dipole moments(in Debye)

\begin{tabular}{lllll}
\hline & & RHF & \multicolumn{2}{c}{ B3LYP/6-31 } \\
Molecule & $6-31++\mathrm{G}$ & $6-31 \mathrm{G}(\mathrm{d}, \mathrm{p})$ & $6-31++\mathrm{G}$ & $6-31 \mathrm{G}(\mathrm{d}, \mathrm{p})$ \\
\hline Proguanil (Chifu et al, 2014) & 10.1635 & - & 9.9257 & - \\
Proguanil derivative & 7.1033 & 7.9887 & 9.0845 & 7.1576 \\
& & & & \\
\hline
\end{tabular}

\section{Quadruapole Moments}

Quadrupole moments provide a second order approximation of the total electron distribution, providing at least a crude idea of its shape. One of the components being significantly larger than the others would represent an elongation of the sphere along that axis. If present, the off-axis components represent trans-axial distortion (stretching or compressing of the ellipsoid). The quadrupole moment for the molecule at both DFT and RHF levels of theory is shown in Table 4 and Table 5 below. The molecules are predicted to be slightly elongated more along the $\mathrm{ZZ}$ axis in gas phase.

Table 4: RHF obtained Quadrupole moments(in Debye)

\begin{tabular}{|c|c|c|c|c|c|c|}
\hline \multirow{2}{*}{ Molecule } & \multicolumn{3}{|c|}{$6-31++G$} & \multicolumn{3}{|c|}{$6-31 G(d, p)$} \\
\hline & $X X$ & YY & $\mathrm{ZZ}$ & $X X$ & YY & ZZ \\
\hline $\begin{array}{l}\text { Proguanil } \\
\text { (Chifu et al 2014) }\end{array}$ & -108.8825 & -102.2247 & -114.9042 & - & - & - \\
\hline $\begin{array}{l}\text { derivative of } \\
\text { Proguanil }\end{array}$ & -97.0849 & -106.0731 & -113.6536 & -101.4627 & -110.0314 & -117.0939 \\
\hline
\end{tabular}


Table 5: B3LYP obtained Quadrupole moments(in Debye)

\begin{tabular}{|l|ccc|ccc|}
\hline \multirow{2}{*}{ Molecule } & \multicolumn{3}{|c|}{$6-31++\mathrm{G}$} & \multicolumn{3}{c|}{$6-31 \mathrm{G}(\mathrm{d}, \mathrm{p})$} \\
\cline { 2 - 7 } & $\mathrm{XX}$ & \multicolumn{1}{|c|}{$\mathrm{YY}$} & $\mathrm{ZZ}$ & $\mathrm{XX}$ & $\mathrm{ZZ}$ \\
\hline $\begin{array}{l}\text { Proguanil (Chifu et } \\
\text { al 2014) }\end{array}$ & -106.2946 & -100.7662 & -112.2982 & - & - \\
\hline Proguanil derivative & -100.9187 & -109.6369 & -115.7719 & -96.5398 & -105.4899 & -111.1272 \\
\hline
\end{tabular}

Table 6: Predicted total thermal energies $(\mathrm{kcal} / \mathrm{mol})$

\begin{tabular}{|l|c|c|l|c|}
\hline \multirow{2}{*}{$\begin{array}{l}\text { Method } \\
\text { Molecule }\end{array}$} & \multicolumn{2}{|c|}{ RHF } & \multicolumn{2}{c|}{ B3LYP } \\
\cline { 2 - 5 } Proguanil [4] & 195.095 & - & 182.682 & - \\
\hline 2-Chloro-Proguanil & 193.332 & 194.531 & 182.214 & 181.439 \\
\hline
\end{tabular}

\section{Polarizability}

Polarizability refers to the way the electrons around an atom redistribute themselves in response to an electrical disturbance, dipole polarizability for the molecule are more on $\mathrm{XX}, \mathrm{YY}$ and $\mathrm{ZZ}$ axis as shown in Table 7 below.

Table 7: Polarizabilities of Proguanil derivative

\begin{tabular}{|l|l|l|l|l|}
\hline \multirow{3}{*}{ orientation } & RHF & B3LYP/6-31G & \multicolumn{2}{|l|}{} \\
\cline { 2 - 5 }$X-31++G$ & $6-31 G(d, p)$ & $6-31++G$ & $6-31 G(d, p)$ \\
\hline$X Y$ & -97.0849 & -101.4627 & -158.6662 & -142.6187 \\
\hline$Y Y$ & 15.8708 & 19.4216 & -4.5987 & -3.6261 \\
\hline$X Z$ & -106.0731 & -110.0314 & -152.5606 & -146.0699 \\
\hline$Y Z$ & -0.1113 & 0.7131 & -3.5103 & -2.4928 \\
\hline$Z Z$ & 1.7072 & 1.4128 & 1.0933 & 1.1643 \\
\hline
\end{tabular}

\section{Vibrational Frequency Analysis}

In general, a molecule with $\mathrm{N}$ atoms has $3 \mathrm{~N}-6$ normal modes of vibration, but a linear molecule has $3 \mathrm{~N}-5$ such modes, as rotation about its molecular axis cannot be observed. 2-Chloro Proguanil molecule with molecular formula $\mathrm{C}_{11} \mathrm{H}_{16} \mathrm{~N}_{5} \mathrm{Cl}$ has a total of 33 atoms and thus $\mathrm{N}=33$; giving 3(33)-6 = 93 possible number of vibrational modes for each IR and Raman frequencies. A vibrational motion for a molecule is when the bonds between atoms within a molecule move. The vibrational coordinate of a normal vibration is a combination of changes in the positions of atoms in the molecule. When the vibration is excited the coordinate changes sinusoidally with a frequency $v$, the frequency of the vibration. Some of the vibrations observed and their descriptions are as follows:

Table 8: Some IR Intense Vibrational Frequencies and their Approximate Description for 3-Chloro

Proguanil at RHF/6-31G(d,p) Level of Theory

\begin{tabular}{|l|l|l|}
\hline S/N & Frequency & Approximate description \\
\hline 1. & 1667.05 & Symmetric stretching of $\mathrm{NH}$ \\
\hline 2. & 1636.83 & Symmetric stretching of $\mathrm{CH}$ \\
\hline 3. & 1952.26 & Symmetric stretching of $\mathrm{CNH}$ \\
\hline 4. & 3255.57 & Symmetric stretching of $\mathrm{CNH}$ \\
\hline 5. & 1667.05 & Symmetric stretching of $\mathrm{CNH}$ \\
\hline 6. & 545.063 & Anti symmetric stretching of CNH \\
\hline 7. & 1308.38 & Bending or Scissoring of the benzyl ring \\
\hline 8. & 1165.08 & Bending or Scissoring of the molecule \\
\hline
\end{tabular}

Table 9: Some IR Intense Vibrational Frequencies and their Approximate Description for 3-Chloro Proguanil at RHF/6-31++G Level of Theory

\begin{tabular}{|l|l|l|}
\hline $\mathrm{S} / \mathrm{N}$ & Frequency & Approximate description \\
\hline 1. & 566.338 & Symmetric stretching of $\mathrm{NH}$ \\
\hline 2. & 802.165 & Distortion of the whole molecule \\
\hline 3. & 1050.2 & Bending or Scissoring $\mathrm{HCH}$ \\
\hline 4. & 1253.94 & Symmetric stretching of $\mathrm{CNH}$ \\
\hline 5. & 1439.96 & bending of $\mathrm{CH}$ and $\mathrm{NC}$ symmetric stretching \\
\hline 6. & 1670.28 & Symmetric stretching of $\mathrm{CNH}$ and $\mathrm{HC}$ bending in the benzyl ring \\
\hline 7. & 1714.57 & Symmetric stretching of $\mathrm{CNH}$ and $\mathrm{HC}$ bending in the benzyl ring \\
\hline 8. & 1794.29 & Distortion of the benzyl ring in the molecule and HN bending \\
\hline 9. & 1918.31 & Symmetric stretching of $\mathrm{NH}$ and bending of $\mathrm{HN}$ \\
\hline
\end{tabular}


BAJOPAS Volume 10 Number 1 June, 2017

Table 10: Some IR Intense Vibrational Frequencies and their Approximate Description for 3-Chloro Proguanil at B3LYP/6-31G(d,p) Level of Theory

\begin{tabular}{|l|l|l|}
\hline S/N & Frequency & Approximate description \\
\hline 1. & 1156.5 & Symmetric Stretching of HNC and bending of H in benzyl ring \\
\hline 2. & 1336.66 & Symmetric Stretching of HNC and bending of H in benzyl ring \\
\hline 3. & 1555.12 & Symmetric Stretching of the whole molecule \\
\hline 4. & 16770.28 & Distortion of benzyl ring \\
\hline 5. & 1767.72 & Symmetric stretching of HCN \\
\hline 6. & 3477.36 & Symmetric Stretching of HN \\
\hline
\end{tabular}

Table 11: Some IR Intense Vibrational Frequencies and their Approximate Description for 3-Chloro Proguanil at B3LYP/6-31++G Level of Theory

\begin{tabular}{|l|l|l|}
\hline $\mathrm{S} / \mathrm{N}$ & Frequency & Approximate description \\
\hline 1. & 1156.50 & bending of the $\mathrm{CH}$ \\
\hline 2. & 1324.80 & Anti Symmetric Stretching of $\mathrm{HC}$ \\
\hline 3. & 1528.54 & bending of the $\mathrm{CH}$ and bending of $\mathrm{H}$ in benzyl ring \\
\hline 4. & 1537.40 & bending of the $\mathrm{CH}$ and $\mathrm{H}$ in benzyl ring \\
\hline 5. & 1643.70 & Distortion of the benzyl ring and breathing of $\mathrm{HCN}$ \\
\hline 6. & 1750.00 & Symmetric Stretching of HNC \\
\hline
\end{tabular}

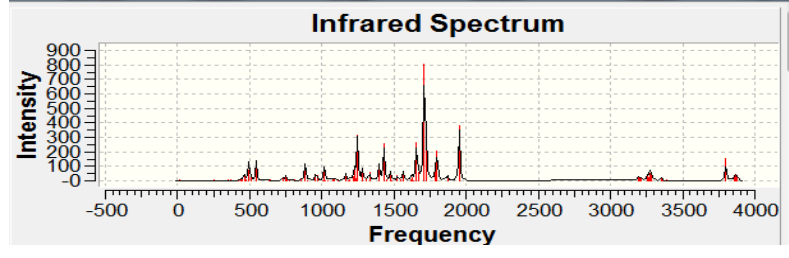

a) 6-31 G(d,p)

Fig. : IR Spectrum at RHF Level of Theory

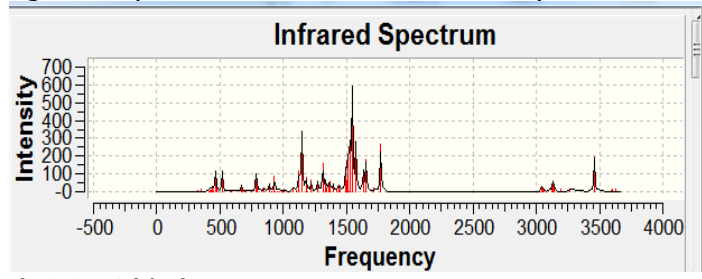

a) 6-31 G(d,p)

Fig. : IR Spectrum at B3LYP Level of Theory

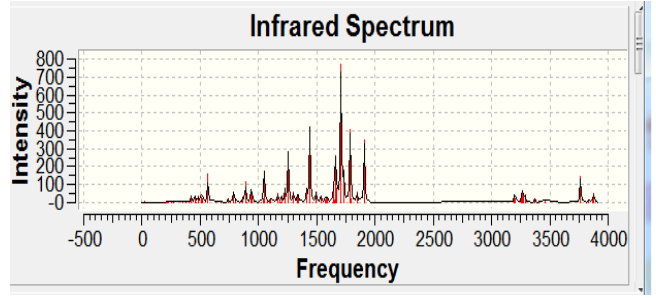

b) $6-31++G$

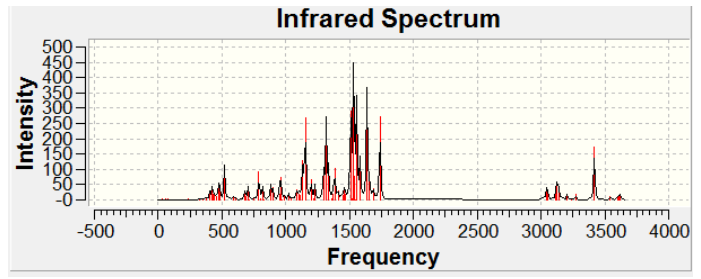

b) $6-31++G$

Table 12: Some Raman Intense Vibrational Frequencies and their Approximate Description for 3Chloro Proguanil at RHF/6-31G(d,p) Level of Theory

\begin{tabular}{|l|l|l|}
\hline S/N & Frequency & Approximate description \\
\hline 1. & 1026.42 & Bending or Scissoring of the $\mathrm{HCH}$ \\
\hline 2. & 1330.05 & Bending or Scissoring of the $\mathrm{HCH}$ and $\mathrm{HNC}$ \\
\hline 3. & 3190.62 & $\mathrm{H}-\mathrm{C}$ Symmetric stretching \\
\hline 4. & 3354.47 & Symmetric stretching of $\mathrm{CH}$ in benzyl ring \\
\hline 5. & 3866.02 & Symmetric stretching of $\mathrm{NH}$ \\
\hline
\end{tabular}

Table 13: Some Raman Intense Vibrational Frequencies and their Approximate Description for 3Chloro Proguanil at RHF/6-31++G Level of Theory

\begin{tabular}{|l|l|l|}
\hline S/N & Frequency & Approximate description \\
\hline 1. & 1112.2 & Benzyl ring symmetric stretching \\
\hline 2. & 1144.29 & Benzyl ring distortion \\
\hline 3. & 3220.47 & Symmetric stretching of $\mathrm{CH}$ \\
\hline 4. & 3264.76 & Anti symmetric stretching of $\mathrm{CNH}$ \\
\hline 5. & 3379.92 & Symmetric stretching of $\mathrm{CH}$ \\
\hline 6. & 3902.56 & Symmetric stretching of $\mathrm{HN}$ \\
\hline 7. & 3849.41 & Symmetric stretching of $\mathrm{NH}$ \\
\hline
\end{tabular}


BAJOPAS Volume 10 Number 1 June, 2017

Table 14: Some Raman Intense Vibrational Frequencies and their Approximate Description for 3Chloro Proguanil at RHF/6-31G(d,p) Level of Theory

\begin{tabular}{|l|l|l|}
\hline S/N & Frequency & Approximate description \\
\hline 1. & 1652.56 & Distortion of the benzyl ring and breathing of HCN \\
\hline 2. & 1767.72 & Symmetric stretching of HNC \\
\hline 3. & 3061.02 & Symmetric stretching of HC \\
\hline 4. & 3149.61 & Anti Symmetric stretching of HC \\
\hline 5. & 3459.65 & Symmetric stretching of HN \\
\hline 6. & 3592.52 & Symmetric stretching of HN \\
\hline
\end{tabular}

Table 15: Some Raman Intense Vibrational Frequencies and their Approximate Description for 3Chloro Proguanil at RHF/6-31++G Level of Theory

\begin{tabular}{|l|l|l|}
\hline S/N & Frequency & Approximate description \\
\hline 1. & 1014.76 & Distortion of the benzyl ring \\
\hline 2. & 1643.70 & Bending of benzyl ring and symmetric stretching of HCN \\
\hline 3. & 1750.00 & Bending of HCN \\
\hline 4. & 3069.88 & Symmetric stretching of HC \\
\hline 5. & 3131.89 & Anti Symmetric stretching of HC \\
\hline 6. & 3140.75 & Anti Symmetric stretching of HC \\
\hline
\end{tabular}

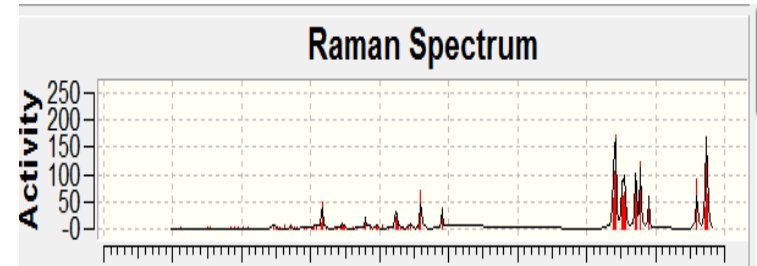

$$
\begin{array}{llllllllll}
-500 & 0 & 500 & 1000 & 1500 & 2000 & 2500 & 3000 & 3500 & 4000
\end{array}
$$

Frequency

Raman Spectrum

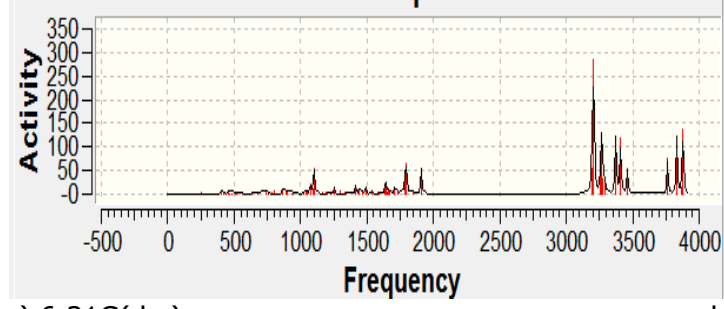

a) $6-31 G(d, p)$

b) $6-31++G$

Fig. : Raman Spectrum at RHF Level of Theory
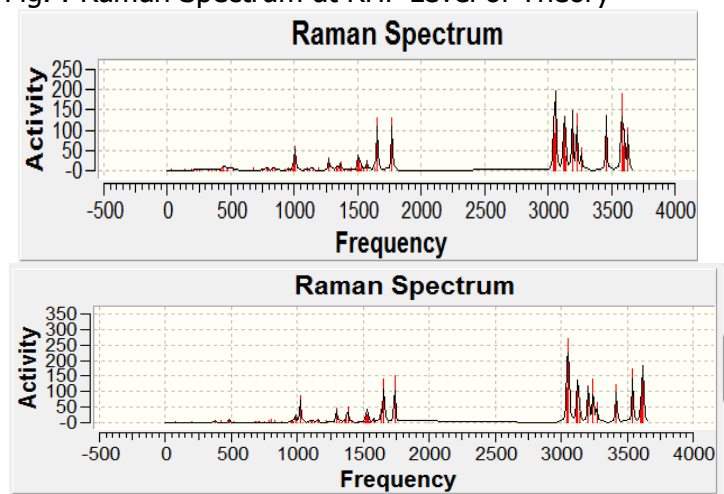

a) $6-31 G(d, p)$

b) $6-31++G$

Fig. : Raman Spectrum at B3LYP Level of Theory 


\section{CONCLUSION AND RECOMMENDATION}

The dipole moment of Proguanil derivative at both levels of theory is less than that obtained for original malaria drug Proguanil. This indicates that Proguanil derivative responds significantly more than Proguanil to an applied electric field. Also, compared to Daraprim, Proguanil has shorter bond lengths and bond angles and higher total energy thus suggesting that the molecule is more stable than Daraprim in gas phase (Geh, 2015). This work provides baseline data for the modeling and subsequent development of future malaria drugs which are derivatives of Proguanil. It is hoped that experimental work will be done in the near future to complement the findings in this work. To compliment this research work, the

\section{REFERENCES}

Becke, A. D. (1988). Density-functional exchangeenergy approximation with correct asymptotic behavior, Physical Review $A$ 38: 3098.

Becke A.D. (1993), "Density Functional Thermo chemistry. III. The role of exact exchange", Journal of Chemical Physics, 98:5648

Chifu E. Ndikilar, Tasiu Z. and L.S. Taura; Bayero Journal of Pure and Applied Sciences , 2014, 7:(2) 64- 68.

Frisch M J, Trucks G W, Schlegel H B, Scuseria G E, Robb M A, Cheeseman J R, Montgomery J A, Vreven Jr T, Kudin K N, Burant J C, Millam $M$, Iyengar S S, Tomasi J, Barone $\mathrm{V}$, Mennucci B, Cossi M, Scalmani G, Rega N, Petersson G A, Nakatsuji $H$, Hada $M$, Ehara M, Toyota K, Fukuda R, Hasegawa J, Ishida M, Nakajima T, Honda Y, Kitao O, Nakai H, Klene M, Li X, Knox J E, Hratchian H P, Cross J B, Adamo C, Jaramillo J, Gomperts R, Stratmann R E, Yazyev O, Austin AJ, Cammi R, Pomelli C, Ochterski J W, Ayala P Y, Morokuma $K$, Voth $G A$, Salvador $P$, Dannenberg J J, Zakrzewski V G, Dapprich S, Danniels A D, Strain M C, Farkas O, Malick D experimental part of this study can be undertaken to ascertain the accuracy of this computational technique. Also, this work can be done using other computational physics soft-wares and results compared with our results in this work. The studied molecule could be studied in other medium to see the effect of the medium on it is physical properties. Solvents that could be considered include ethanol, hexane, hydronaphthalenes, Carbon disulfide, Chloroform, and other organic solvents.

\section{Acknowledment}

We wish to acknowledge Sule Lamido University Research Committee for providing the funds for this research.

K, Rabuck A D, Raghavachari K, Foresman J B, Ortiz J V, Cui Q, Baboul A G, Clifford S, Cioslowski J, Stefanov B B, Liu G, Liashenko A, Piskorz $\mathrm{P}$, Komaromi I, Martin R L, Fox D J, Keith $T$, Al-Laham M A, Peng C Y, Nanayakkara A, Challacombe M, Gill PMW, Johnson B, Chen W, Wong M W, Gonzalez C, and Pople J A, Gaussian, Inc., Wallingford CT, 2004 Gaussian 03, Revision C.02 (2004).

Geh W. Ejuh , S. Nouemo, Chifu E. Ndikilar, F. T. Nya and Njaka J. Marie, Journal of Advances in Physics 10(2):2696 - 2714, 2015.

Lee, C., W. Yang, and R. G. Parr, (1988). Development of the Colle-Salvetti correlation-energy formula into a functional of the electron density, Physical Review B 37, 785.

Sachs, J.; Malaney, P. Nature, 2002, 415, 680-685.

Schwarz, O.; Brun, R.; Bats, J. W.; Schmalz, H-G. Tetrahedron Lett., 2002, 43, 1009-1013.

Singh, C.; Srivastav, N. C.; Puri, S. K. Bioorg. \& Med. Chem. Lett., 2002, 12, 2277-2279.

Snow, R. W.; Guerra, C. A.; Noor, A. M.; Myint, H. Y. Nature, 2005, 434, 214-217. 